\title{
Potential biomarkers for the therapeutic efficacy of sorafenib, sunitinib and everolimus
}

\author{
YASUSHI NAKAI, MAKITO MIYAKE, YOSUKE MORIZAWA, SHUNTA HORI, YOSHIHIRO TATSUMI, \\ SATOSHI ANAI, SAYURI ONISHI, NOBUMICHI TANAKA and KIYOHIDE FUJIMOTO
}

Department of Urology, Nara Medical University, Kashihara, Nara 634-8522, Japan

Received June 15, 2016; Accepted October 24, 2016

DOI: 10.3892/or.2016.5232

\begin{abstract}
We examined extracellular signal-regulated kinase (ERK), 4E-binding protein 1 (4EBP1) and p70 ribosomal S6 kinase (p70) as potential biomarkers for pretreatment prediction of the prognosis of patients with metastatic renal cell carcinoma (RCC) treated with sorafenib, sunitinib or everolimus. 786-O and 769-P cells were treated with sorafenib, sunitinib and everolimus. The expression of phosphorylated/total ERK, phosphorylated/total 4EBP1 and phosphorylated/total p70 was evaluated using western blotting. ERK, 4EBP1 and p70 were knocked down by siRNA in 786-O and 769-P cells. Then, the viability after treatment with each drug was assessed. Expression of phosphorylated (phospho)-ERK, -4EBP1 and -p70 was immunohistochemically evaluated in radical nephrectomy specimens and correlated with progression-free survival during treatment with each molecular targeting agent. Sorafenib inhibited the expression of phospho-ERK and -4EBP1 in 769-P cells; sunitinib, phospho-ERK and -4EBP1 in 786-O and 769-P cells; and everolimus, phospho-p70 in 786-O and 769-P cells. Knockdown of ERK reduced sensitivity to sorafenib in both cell lines, knockdown of ERK and 4EBP1 reduced sensitivity to sunitinib in 769-P cells, and knockdown of 4EBP1 and p70 reduced sensitivity to everolimus in 786-O cells. High expression of phospho-ERK, -4EBP1 and -p70 correlated
\end{abstract}

Correspondence to: Dr Kiyohide Fujimoto, Department of Urology, Nara Medical University, 840 Shijo-cho, Kashihara, Nara 634-8522, Japan

E-mail: kiyokun@naramed-u.ac.jp

Abbreviated: c-Kit, c-Kit protein; 4EBP1, 4E-binding protein 1; ERK, extracellular signal-regulated kinase; Flt-3, FMS-like tyrosine kinase-3; mTOR, mammalian target of rapamycin; MSKCC, Memorial Sloan Kettering Cancer Center; mRCC, metastatic renal cell carcinoma; p70, p70 ribosomal S6 kinase; PDGFR, platelet-derived growth factor receptor; siRNA, short interference RNA; RECIST, response evaluation criteria in solid tumor; VEGF, vascular endothelial growth factor; VEGFR, vascular endothelial growth factor receptors

Key words: 4E-binding protein 1, extracellular signal-regulated kinase, everolimus, ribosomal S6 kinase, sorafenib, sunitinib with better progression-free survival in patients treated with sorafenib, sunitinib and everolimus, respectively. Our results indicate that phospho-ERK, -4EBP1 and/or -ERK, and phospho-p70 can be used as biomarkers for the therapeutic efficacy of sorafenib, sunitinib and everolimus, respectively.

\section{Introduction}

At present, many molecular targeted drugs are being used in the treatment of metastatic renal cell carcinoma (mRCC). Sorafenib, sunitinib and everolimus have been used for the last 10 years in Japan. Sorafenib initially was identified as a Raf kinase inhibitor and also inhibits vascular endothelial growth factor receptors (VEGFR)-1, -2 and -3 , platelet-derived growth factor receptor- $\beta$ (PDGFR- $\beta$ ), FMS-like tyrosine kinase-3 (Flt-3), c-Kit protein (c-Kit) and RET receptor tyrosine kinases $(1,2)$. Treatment with sorafenib prolongs progression-free survival (PFS) in patients with advanced clear cell renal cell carcinoma (3). Sunitinib is a multiple kinase inhibitor with activity against VEGFR-1, -2 and -3 , PDGFR- $\alpha$ and $-\beta, c-K i t$ and Flt-3 (4,5). Furthermore, Motzer et al (6) reported the efficacy of sunitinib in a phase 3 study. Everolimus is the mammalian target of rapamycin (mTOR) $\mathrm{C} 1$ inhibitor and prolongs PFS in patients with $\mathrm{mRCC}$ that had progressed on other targeted therapies (7).

Markers predicting the prognosis or therapeutic efficacies of molecular targeting agents in patients with mRCC have been reported. For example, the development of hypertension during sunitinib treatment was a positive predictive factor associated with a significantly longer PFS and OS in patients with mRCC (8). Patients with symptomatic hypothyroidism experienced significantly longer PFS during the treatment of sunitinib (9). Furthermore, Di Fiore et al (10) reported severe clinical toxicities that are correlated with survival in patients with advanced renal cell carcinoma treated with sunitinib and sorafenib. However, it is impossible to know these markers before initiation of treatment. Useful pretreatment predictive biomarkers are needed to decide which molecular target agent(s) should be selected. Funakoshi et al (11) reported that although several promising biomarkers for VEGF-targeted therapy have been found, none of them has satisfied the determination of level I evidence.

Sorafenib works by inhibiting RAF and VEGF and then mainly inhibit RAF/MEK/extracellular signal-regulated 
kinase (ERK) pathway correlated with tumor growth inhibition (1). Sunitinib is a multiple kinase inhibitor and then inhibits the RAF/MEK/ERK and PI3K/Akt/mTOR pathways. Everolimus inhibits mTORC1, which has been shown to directly phosphorylate p70 ribosomal S6 kinase (p70) and 4E-binding protein 1 (4EBP1) (12). Based on these facts, we focused on three molecules, ERK, 4EBP1 and p70, as pretreatment predictive markers for responsiveness of tumor and prognosis of patients treated with three molecular targeting agents sorafenib, sunitinib and everolimus.

\section{Materials and methods}

Cell culture. Two human clear cell renal carcinoma cell lines, 786-O and 769-P (American Type Culture Collection, Manassas, VA, USA) were maintained in RPMI-1640 growth medium (Nissui, Tokyo, Japan) supplemented with $10 \%$ fetal bovine serum (ICN Biomedicals, Aurora, OH, USA), 100 U/ml penicillin and $100 \mu \mathrm{g} / \mathrm{ml}$ streptomycin (Gibco, Grand Island, $\mathrm{NY}$, USA) in a standard humidified incubator at $37^{\circ} \mathrm{C}$ in a $5 \% \mathrm{CO}_{2}$ atmosphere.

Molecular target agents. Sorafenib tosylate, sunitinib malate and everolimus were purchased from LC Laboratories (Woburn, MA, USA) and dissolved in dimethyl sulfoxide at a concentration of 200, 40 and $100 \mathrm{mg} / \mathrm{ml}$, respectively. The stock solutions were stored at $-20^{\circ} \mathrm{C}$ before use.

Western blotting. Protein extraction, measurement of protein concentration and immunoblotting were performed as described previously (13). Primary antibodies used in this study were total p44/42 MAPK (t-ERK1/2) rabbit polyclonal (no. 9102, dilution 1:1,000), rabbit polyclonal phosphorylated (phospho)-ERK1/2 (p-ERK1/2; no. 9644, dilution 1:1,000), rabbit monoclonal total 4EBP1 (no. 9102, dilution 1:1,000), rabbit phospho-4EBP1 (no. 2855, dilution 1:1,000), rabbit monoclonal p70 (no. 2708, dilution 1:1,000) (all from Cell Signaling Technology, Danvers, MA, USA), mouse monoclonal phospho-p70 (Thr389; MABS82; dilution 1:1,000; Merck Millipore, Bedford, MA, USA), and mouse monoclonal actin- $\beta$ (clone AC-15, 1:3,000 dilution; Sigma-Aldrich, St. Louis, MO, USA) which was used as an internal loading control were incubated overnight at $4^{\circ} \mathrm{C}$. The membranes were then hybridized with the secondary antibody conjugated to horseradish peroxidase for $1 \mathrm{~h}$ at room temperature. Finally, the bound secondary antibody was detected using SuperSignal West Pico Chemiluminescent Substrate (Pierce Chemical, Rockford, IL, USA).

Transfection of short interference RNA (siRNA) against total $E R K$, total $4 E B P 1$ and total $p 70$. For the reproducible siRNA transfection, cells were seeded at a density of $5 \times 10^{3}$ cells $/ \mathrm{cm}^{2}$ in 35-mm dishes and transfected with $10 \mathrm{nM}$ siRNA using Lipofectamine RNAiMAX transfection reagent (Invitrogen, Carlsbad, CA, USA) using the reverse transfection method according to the manufacturer's recommended protocol. The medium containing complex of siRNA and transfection reagent was replaced routinely with fresh growth medium at $24 \mathrm{~h}$ after the transfection. Three validated siRNA against ERK1/2 (SignalSilence no. 6560), 4EBP1 (no. 6414), and p70 (no. 6566) and nontargeting control siRNA (no. 6568) were purchased from Cell Signaling Technology.

In vitro cytotoxicity assay. The cells were seeded in a 96-well plate at a density of 2,000 cells/well for 786-O and 769-P in a growth medium and incubated for $24 \mathrm{~h}$. They were treated with the indicated concentrations of sorafenib, sunitinib and everolimus. After incubating the plates for $72 \mathrm{~h}$, a cell viability assay was performed using Cell Counting kit-8 (Dojindo, Kumamoto, Japan) and quantified using a microplate autoloader (Infinite 200M PRO; Tecan, Männedorf, Switzerland) according to the manufacturer's directions.

Patients. Patients who underwent radical nephrectomy and treatment of sorafenib, sunitinib or everolimus for mRCC were enrolled. The numbers of patients treated with sorafenib as first, second and third line were 18, 1 and 2, respectively; those treated with sunitinib as first, second and fourth line were 19,5 and 1, respectively; and those treated with everolimus as first, second and third line were 7,9 and 5, respectively (Table I). The institutional review board of Nara Medical University approved this study.

CT was performed every 2-3 months to evaluate tumor progression in all patients. When a rapid progression was suspected by patients' symptoms, CT was performed. Progression was defined when a new lesion appeared or a $25 \%$ increase in tumor area was detected by CT according to response evaluation criteria in solid tumor (RECIST) guidelines during the treatment of each molecular targeting agent.

Tissue samples and immunocytochemistry. Immunohistochemistry staining for paraffin-embedded section from radical nephrectomy specimens was performed as described previously (14) with a streptavidin-biotin complex method using the Histofine SAB-PO kit (Nichirei Co., Tokyo, Japan) according to the manufacturer's instructions. The specificity of the antibody was assessed by performing a secondary antibody-only control experiment. Slides were counterstained with Meyer's hematoxylin and mounted with malinol (both from Muto Chemical, Tokyo, Japan).

The primary antibodies and incubation conditions were as follows: i) rabbit polyclonal anti-phospho-ERK (Sigma-Aldrich), 1:100 dilution, room temperature for $1 \mathrm{~h}$; ii) mouse monoclonal anti-phospho-4EBP1 (BD Transduction Laboratories), 1:100 dilution, $4^{\circ} \mathrm{C}$ overnight; and iii) mouse monoclonal anti-phospho-p70 (clone MIB-1; Dako Japan, Kyoto, Japan), 1:500, $37^{\circ} \mathrm{C}$ overnight.

Phospho-ERK, -4EBP1 and -p70 staining was evaluated as follows: tumors with $10 \%$ cells with weak staining were scored as 0 ; tumors with $10 \%$ cells with weak staining or $20 \%$ cells with intermediate to strong staining were scored as 1 ; and tumors with $20 \%$ cells with intermediate to strong staining were scored as $2(14,15)$. A staining score of 1 or 2 was considered to represent strong. Two investigators (Yasushi Nakai and Makito Miyake), who were both blinded to the patient data, evaluated the scores. A third investigator (Satoshi Anai) reviewed discrepancies and rendered a score.

Statistical analysis. Statistical analysis was performed with SPSS for Windows (version 20; IBM SPSS, Armonk, NY, 
Table I. Patient characteristics.

\begin{tabular}{|c|c|c|c|}
\hline Patient characteristics & $\begin{array}{c}\text { Sorafenib } \\
\quad(n=21)\end{array}$ & $\begin{array}{l}\text { Sunitinib } \\
(n=25)\end{array}$ & $\begin{array}{l}\text { Everolimus } \\
\quad(n=12)\end{array}$ \\
\hline Men/women & $18 / 3$ & $19 / 6$ & $11 / 1$ \\
\hline Age, years, median (range) & $60(42-81)$ & $53(33-78)$ & $61(33-76)$ \\
\hline \multicolumn{4}{|l|}{ Pathology } \\
\hline Clear cell/non-clear cell & $18 / 3$ & $20 / 5$ & $10 / 2$ \\
\hline \multicolumn{4}{|l|}{ Line } \\
\hline First/second/third/fourth & $18 / 1 / 2 / 0$ & $19 / 5 / 0 / 1$ & $7 / 4 / 1 / 0$ \\
\hline \multicolumn{4}{|l|}{ MSKCC risk classification } \\
\hline Favorable/intermediate/high & $4 / 11 / 6$ & $7 / 13 / 5$ & $4 / 8 / 0$ \\
\hline \multicolumn{4}{|l|}{ Heng risk classification } \\
\hline Favorable/intermediate/high & $6 / 14 / 1$ & $8 / 15 / 2$ & $3 / 9 / 0$ \\
\hline
\end{tabular}

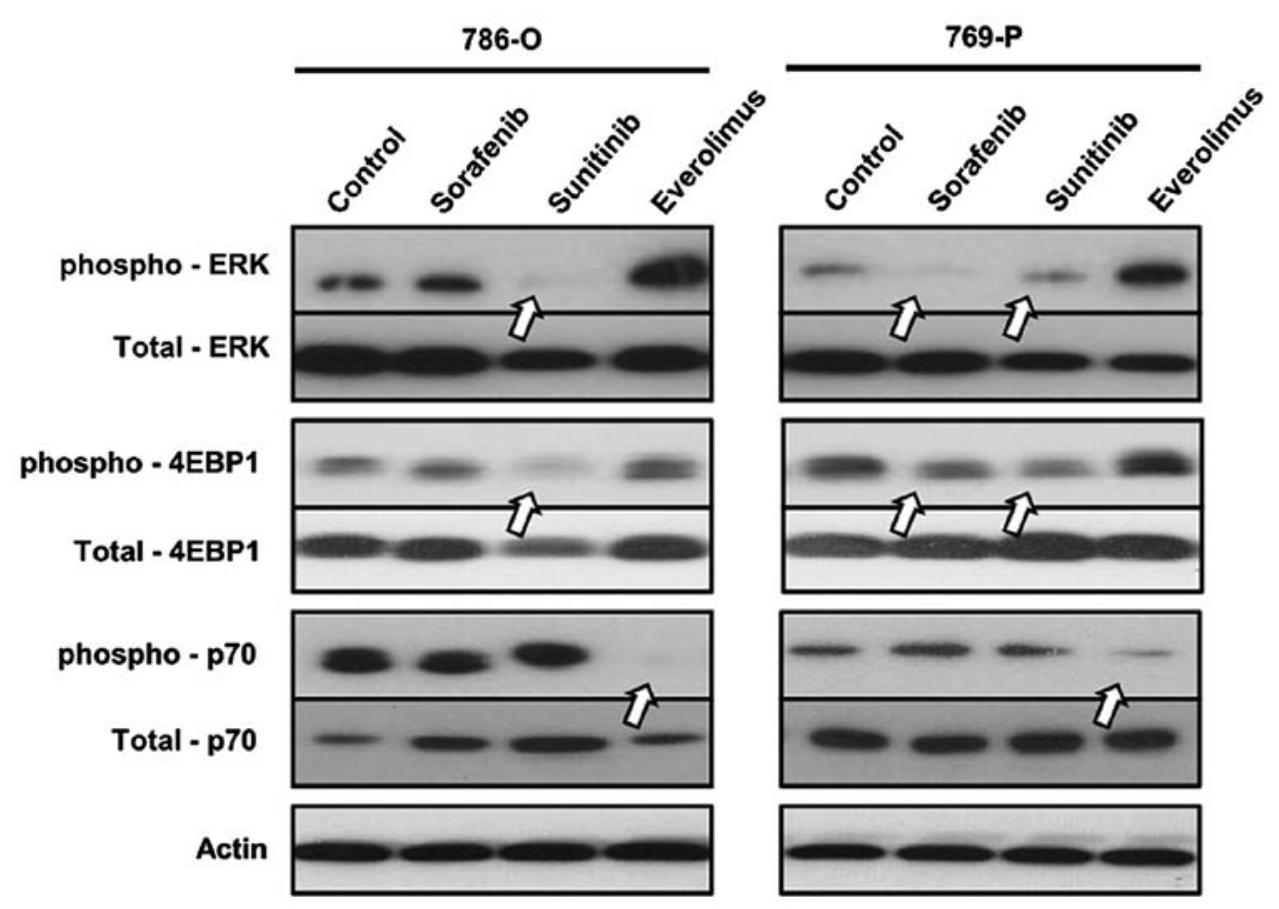

Figure 1. Expression of phospho-extracellular signal-regulated kinase (ERK), total ERK, phospho-4E-binding protein 1 (4EBP1), total 4EBP1, phospho-p70 ribosomal S6 kinase (p70), and total p70 after treatment with sorafenib, sunitinib and everolimus using western blotting in 786-O and 769-P cells.

USA). Group variables were compared using the $\chi^{2}$ test. The Mann-Whitney $U$ test was used to analyze the differences between two continuous variables. PFS rates during each treatment were estimated using the Kaplan-Meier method. The log-rank test was used to compare PFS rates. A P-value $<0.05$ was considered statistically significant.

\section{Results}

Expression of phospho-ERK, -4EBPl and -p70 treated with sorafenib, sunitinib and everolimus. Sorafenib inhibited the expression of phospho-ERK and -4EBP1 in 769-P cells and sunitinib inhibited the expression of phospho-ERK and -4EBP1 in 786-O and 769-P cells. When treated with everolimus, the expression of phospho-p70 was inhibited in both cell lines (Fig. 1).

Gene silencing of ERK, 4EBP1 and $p 70$. We demonstrated successfully gene silencing of total ERK, 4EBP1 and 70 by the indicated siRNA (Fig. 2). To confirm the effect of downregulation of the indicated genes, cell viability assay was performed. When the viability of cells that knocked a molecule down is increased after treatment with molecular target agents, it means that the molecular target agents work through the molecule or the pathway including the molecule. With respect to sorafenib, the cells knocked down ERK reduced sensitivity to sorafenib in both cell lines (Fig. 3A). 769-P cells knocked down ERK and 4EBP1 reduced sensitivity to sunitinib (Fig. 3B) and 


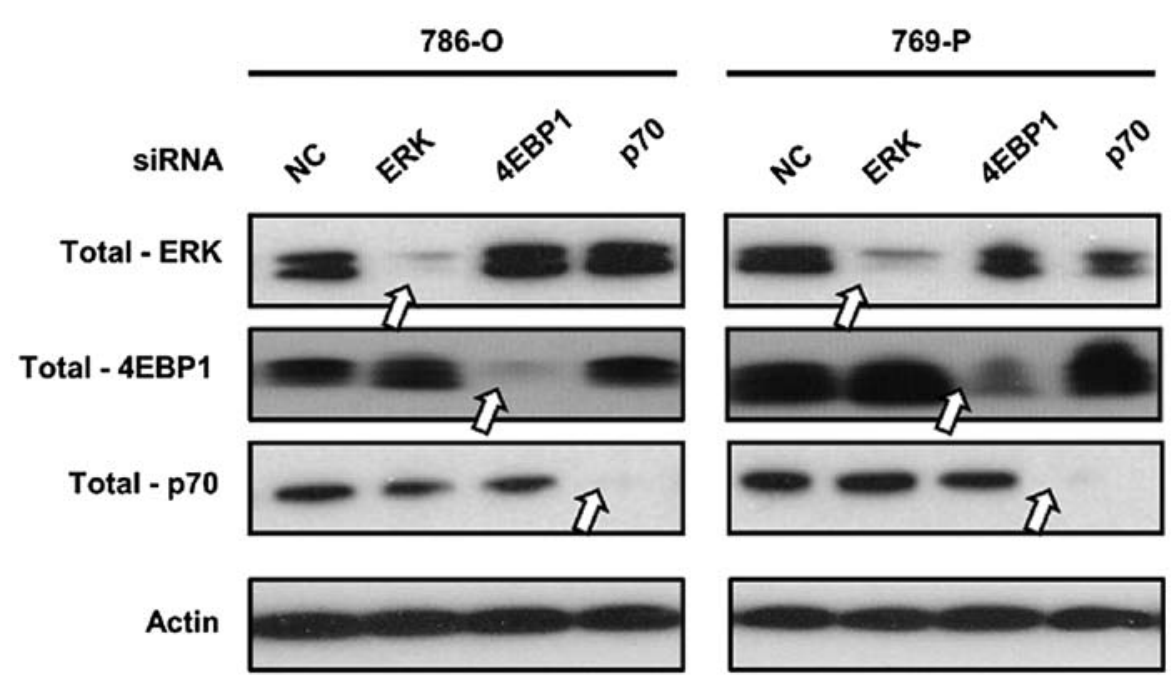

Figure 2. Negative control (NC), expressions of total extracellular signal-regulated kinase (ERK), 4E-binding protein 1 (4EBP1) and p70 ribosomal S6 kinase (p70) after their knockdown by short interference RNA.

Table II. Maximum response of each treatment.

A, Maximum response in patients who were treated with sorafenib as the first line

\begin{tabular}{llcc}
\hline Expression of phospho-ERK & PR & SD & PD \\
\hline Low $(\mathrm{n}=13), \mathrm{n}(\%)$ & $1(7.6)$ & $6(46.2)$ & $6(46.2)$ \\
High $(\mathrm{n}=5), \mathrm{n}(\%)$ & $2(40.0)$ & $3(60.0)$ & 0 \\
Chi-squared test $\mathrm{P}=0.025$ & & & \\
\hline
\end{tabular}

$\mathrm{B}$, Maximum response in patients who were treated with sunitinib as the first line

\begin{tabular}{lccc}
$\begin{array}{l}\text { Expression of phospho-ERK } \\
\text { plus 4EBP1 }\end{array}$ & PR & SD & PD \\
\hline Low $(\mathrm{n}=4), \mathrm{n}(\%)$ & 0 & $1(25.0)$ & $3(75.0)$ \\
High $(\mathrm{n}=7), \mathrm{n}(\%)$ & $2(28.6)$ & $5(71.4)$ & 0 \\
Chi-squared test $\mathrm{P}=0.0067$ & & & \\
\hline
\end{tabular}

C, Maximum response in patients who were treated with everolimus

\begin{tabular}{lccc}
\hline Expression of phospho-p70 & PR & SD & PD \\
\hline Low $(\mathrm{n}=6), \mathrm{n}(\%)$ & 0 & $4(66.7)$ & $2(33.3)$ \\
High $(\mathrm{n}=6), \mathrm{n}(\%)$ & 0 & $5(83.3)$ & $1(16.7)$ \\
Chi-squared test $\mathrm{P}=0.39$ & & & \\
\hline
\end{tabular}

$\mathrm{PR}$, partial response; SD, stable disease; $\mathrm{PD}$, progression disease; ERK, extracellular signal-regulated kinase; 4EBP1, 4E-binding protein 1; p70, p70 ribosomal S6 kinase.

786-O cells knocked down 4EBP1 and p70 reduced sensitivity to everolimus (Fig. 3C).
Correlation between expression of phosphorylated molecules and progression-free survival. In patients treated with sorafenib, high expression of phospho-ERK in nephrectomy specimens correlated with better PFS during treatment with sorafenib ( $\mathrm{P}=0.049)$ (Fig. 4). In addition, in patients who were treated with sorafenib as the first line, no patient who showed high expression of phospho-ERK in nephrectomy specimens showed progression of disease in maximum response (Table II-A). In patients treated with sunitinib, high expression of phospho-4EBP1 correlated with better PFS during treatment with sunitinib $(\mathrm{P}=0.04)$ (Fig. 5). Furthermore, we compared PFS in patients whose specimens showed high expression of phospho-ERK and -4EBP1 $(n=9)$ with those showing low expression of phospho-ERK and -4EBP1 $(n=5)$. PFS in patients showing high expression of both was significantly better $(\mathrm{P}=0.0052)$ (Fig. 5C). In patients who were treated with sunitinib as the first line, no patient who showed high expression of phospho-ERK and 4EBP1 in nephrectomy specimens showed progression of disease in maximum response (Table II-B). In patients treated with everolimus, high expression of phospho-p70 and low expression of phospho-ERK correlated with good PFS during treatment with everolimus ( $\mathrm{P}=0.046$ and $\mathrm{P}=0.01$, respectively) (Fig. 6).

\section{Discussion}

Sorafenib suppressed phospho-ERK and -4EBP1 in 769-P cells (Fig. 1). Furthermore, 786-O and 769-P cells with knocked down ERK by siRNA reduced sensitivity to sorafenib (Fig. 3). The results of the in vivo study showed that sorafenib could work mainly through the RAF/MEK/ERK pathway, and expression of phospho-ERK can be a predictive marker of therapeutic efficacy of sorafenib. Furthermore, high expression of phospho-ERK in nephrectomy specimens significantly correlated with good prognosis (Fig. 4). To the best of our knowledge, no studies have evaluated the correlation between phospho-ERK and therapeutic efficacy of sorafenib $(11,16)$. Zhang et al (17) found that phospho-ERK inhibition by sorafenib in SMMC-7721 cells, hepatocellular carcinoma 
A Sorafenib

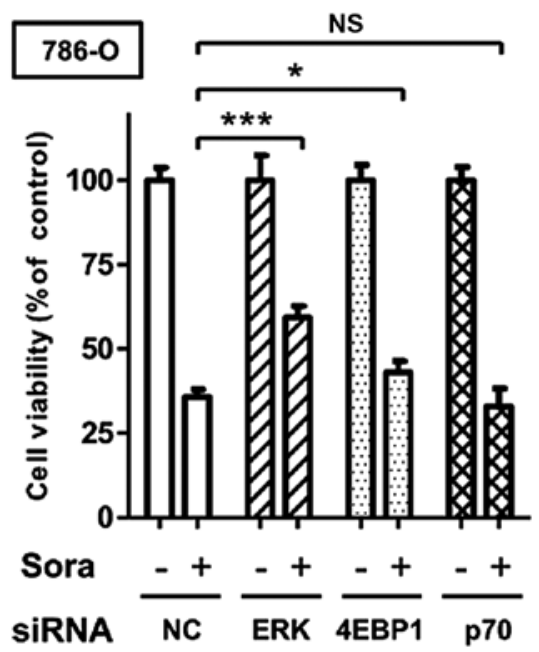

B Sunitinib

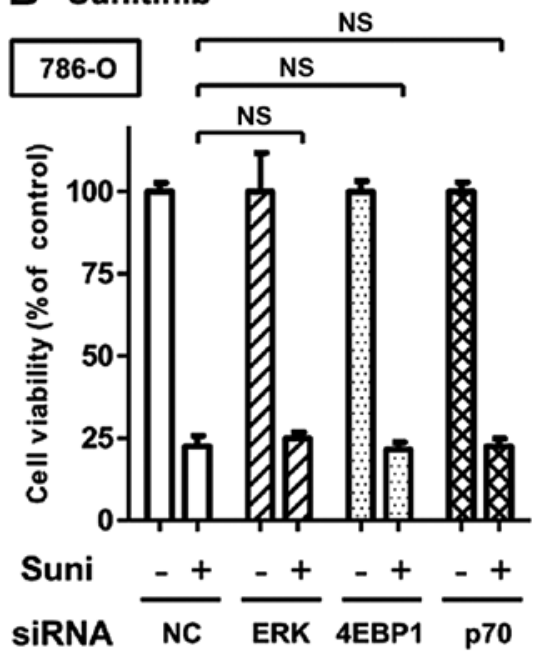

C Everolimus

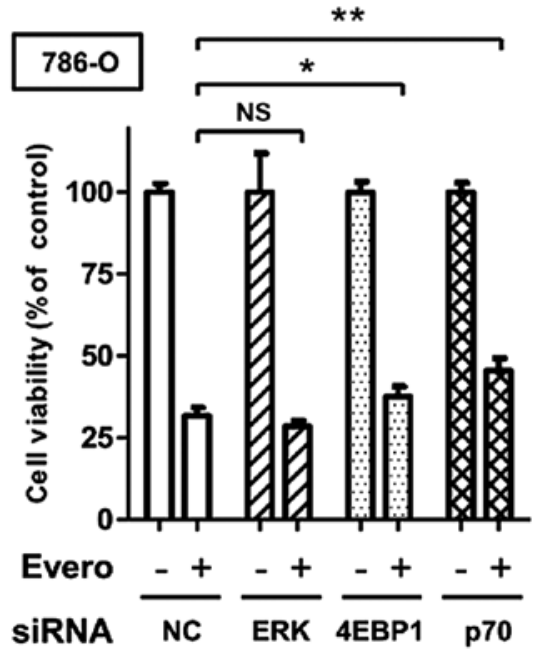

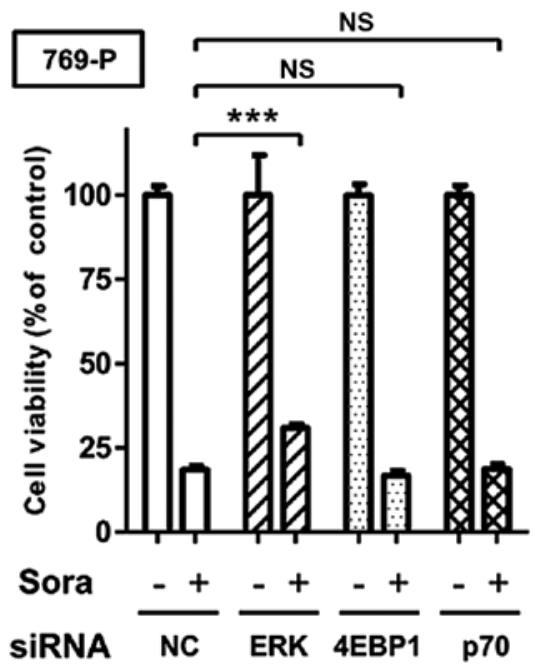
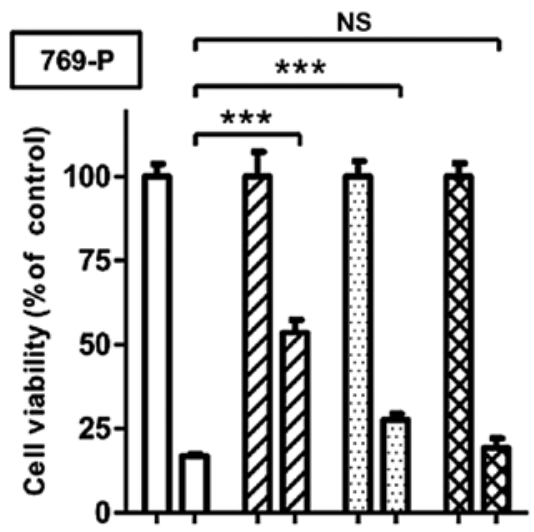

SiRNA $\frac{-+}{\text { NC }} \frac{-+}{\text { ERK }} \frac{-+}{4 \text { EBP1 }} \frac{-+}{\text { p70 }}$

Figure 3. Viability of 786-O and 769-P cells with each molecule knocked down by short interference RNA after treatment with (A) sorafenib (Sora), (B) sunitinib (Suni) and (C) everolimus (Eve). Paired t-test: ${ }^{*} \mathrm{P}<0.05,{ }^{* *} \mathrm{P}<0.01$ and ${ }^{* * *} \mathrm{P}<0.005$.

cell line with lower phospho-ERK levels, was significantly weaker than the other three hepatocellular carcinoma cell lines with relatively higher phospho-ERK levels. Liu et al (18) reported that sorafenib blocks the RAF/MEK/ERK pathway, inhibits tumor angiogenesis and induces tumor cell apoptosis in hepatocellular carcinoma model PLC/PRF/5. Although 

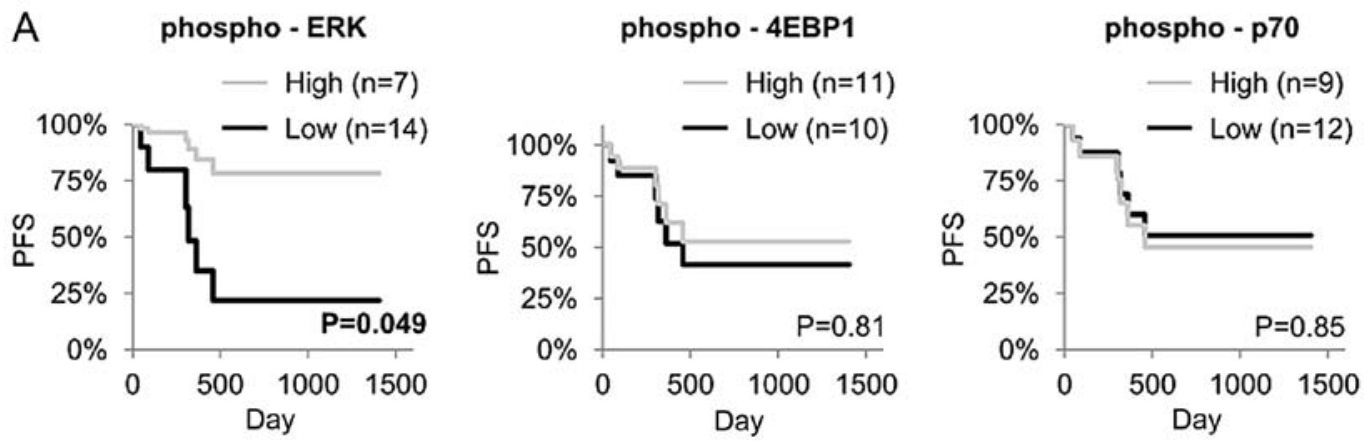

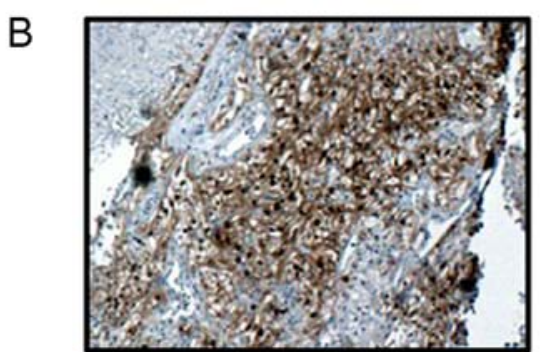

High expression

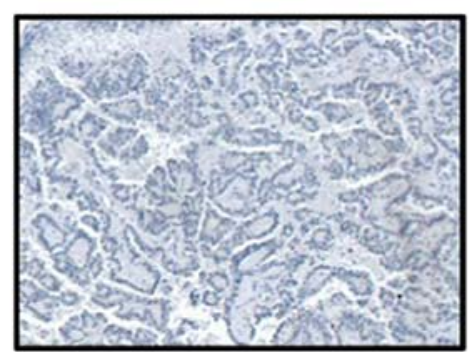

Low expression

Figure 4. (A) Progression-free survival curves of patients treated with sorafenib. The gray line shows high expression of each phosphorylated molecule and the black line shows low expression. (B) Immunohistochemical staining of phospho-extracellular signal-regulated kinase (ERK). (Magnification, x100).
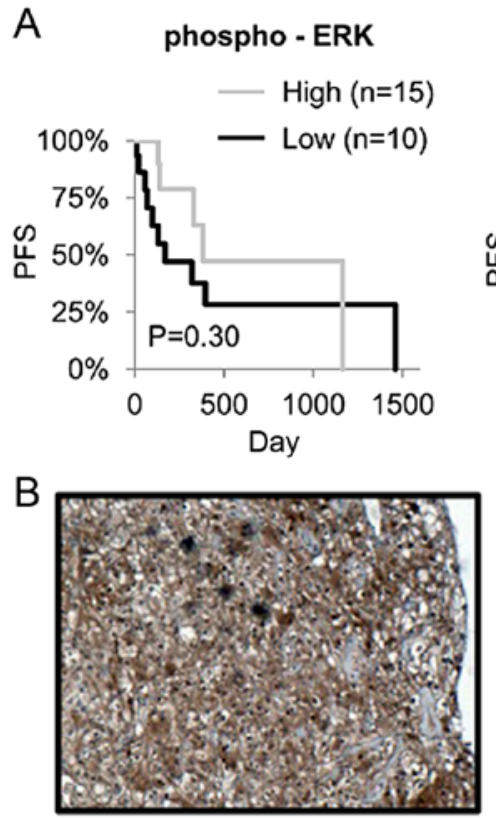

High expression
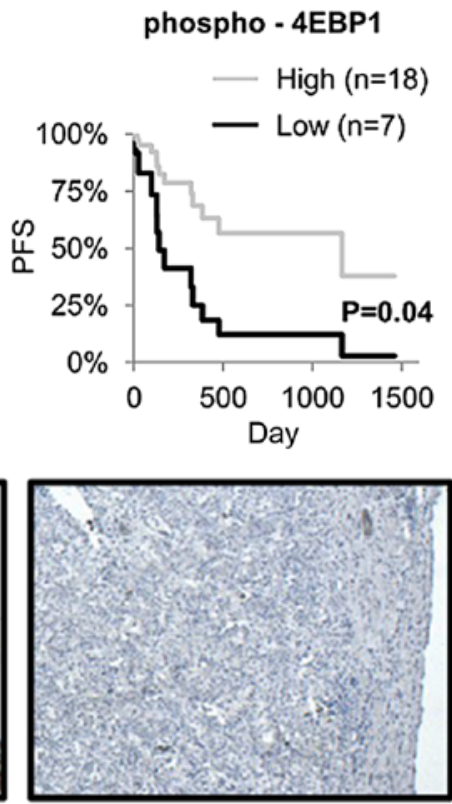

Low expression

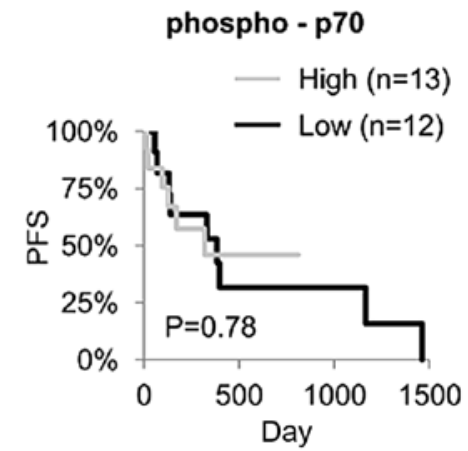

C phospho - ERK + 4EBP1

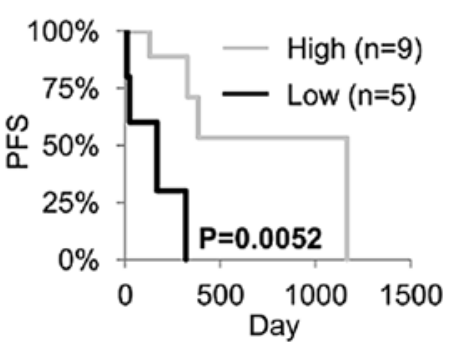

Figure 5. (A) Progression-free survival curves of patients treated with sunitinib. The gray line shows high expression of each phosphorylated molecule and the black line shows low expression. (B) Immunohistochemical staining of phospho-4E-binding protein 1 (4EBP1). (Magnification, x100). (C) Progression-free survival curves of patients showing high expression of phospho-extracellular signal-regulated kinase (ERK) plus-4EBP1 and low expression.

these results were on hepatocellular carcinoma, their results are compatible to our results. In renal cell carcinoma, high expression of phospho-ERK in nephrectomy specimens is associated with advanced and aggressive pathologic features (19). Oka et al (20) revealed the correlation between ERK1/2 activation and high tumor grade. These results suggest that high expression of phospho-ERK in renal cell carcinoma is a poor prognosis predictor. On the other hand, our results indicated that sorafenib can be efficacious in cases of renal cell carcinoma with high expression of phospho-ERK. These results indicated sorafenib can be efficacious in cases of aggressive renal cell carcinoma with high expression of phospho-ERK.

Sunitinib suppressed the expression of phospho-ERK and $-4 \mathrm{EBP} 1$ in both cell lines (Fig. 1) and reduced sensitivity to 769-P cells with ERK and 4EBP1 knocked down (Fig. 3). Based on these results, expression of phospho-4EBP1 and 
A
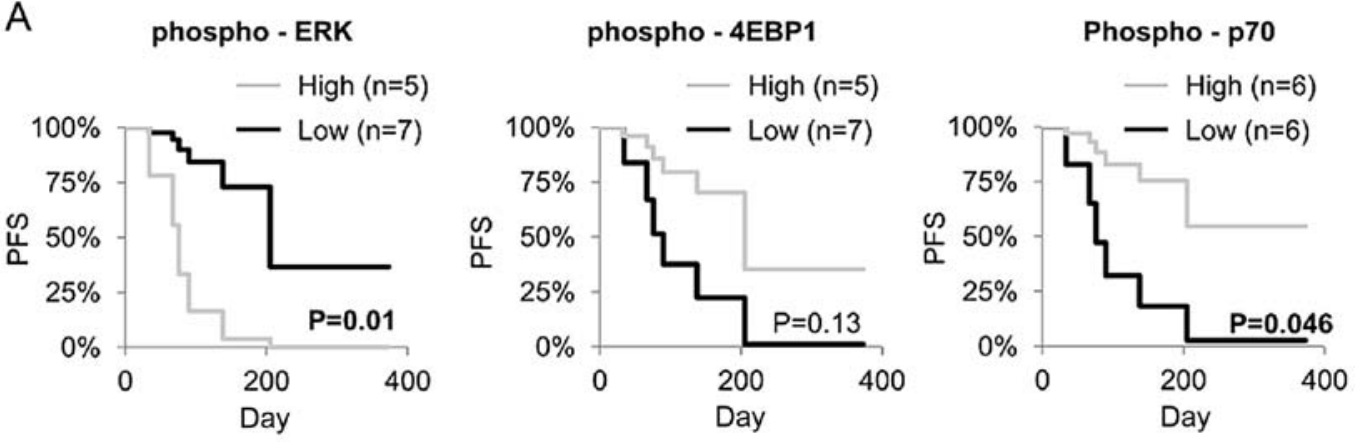

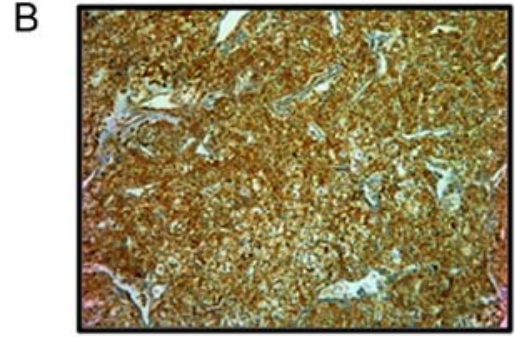

High expression

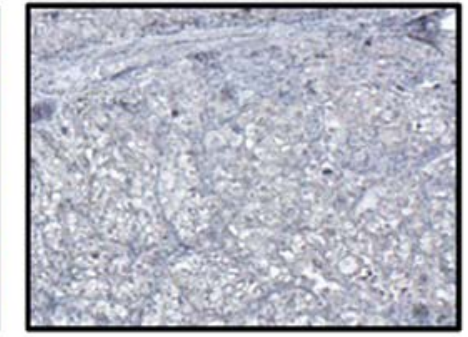

Low expression

Figure 6. (A) Progression-free survival curves of patients treated with everolimus. The gray line shows high expression of each phosphorylated molecule and the black line shows low expression. (B) Immunohistochemical staining of phospho-p70 ribosomal S6 kinase (p70). (Magnification, x100).

ERK can be a predictive marker of therapeutic efficacy of sunitinib. In the present clinical samples, high expression of phospho-4EBP1 predicted better prognosis during treatment of sunitinib (Fig. 5A). PFS in patients showing high expression of phospho-ERK and -4EBP1 was significantly better $(\mathrm{P}=0.0052)$ (Fig. 5C). To our knowledge, no studies have evaluated the correlation between phospho-4EBP1 or -ERK and therapeutic efficacy of sunitinib in renal cell carcinoma $(11,16)$. However, previous studies also have shown that high VEGFR-2 expression associates significantly with a good response to sunitinib treatment in renal cell carcinoma $(21,22)$. Trinh et al reported VEGFR-2 had significant correlation with 4EBP1 (23). This suggests that phospho-4EBP1 can be a more accurate marker to predict therapeutic efficacy of sunitinib. With respect to ERK, Takeuchi et al (24) reported that sunitinib treatment inhibits the proliferation of drug-resistant ERK1/2-overexpressing bladder cancer cells. Fenton et al (25) reported that sunitinib targets the cytosolic MEK/ERK pathways in thyroid cancer cell lines. These results are compatible with our results in the present in vivo study. Therefore, high expression of phospho-4EBP1 or high expression of phospho-4EBP1 plus phospho-ERK can be a predictive marker of therapeutic efficacy for sunitinib.

Everolimus suppressed the expression of phospho-p70 in both cell lines (Fig. 1) and reduced sensitivity to 786-O cells with p70 knocked down in the present study (Fig. 3). Robb et al (26) reported the mTOR/p70 kinase signaling pathway is activated in most clear cell renal cell carcinomas and the growth of renal clear cell carcinoma derived cell lines is inhibited by rapamycin. This result supported our results. Furthermore, in clinical samples, high expression of phospho-p70 predicted better prognosis with the treatment of everolimus (Fig. 6). Nishikawa et al (27) evaluated the correlation between phospho-AKT, -4EBP1 and -p70 and the therapeutic efficacy of mTOR inhibitor. The weak expression of phospho-4EBP1 predicts better PFS. This result differs from our results. The reasons for this discrepancy can be i) our study population was very small, ii) the number of patients who received mTOR inhibitor as first line was higher in their study than that in this study, iii) clear cell renal cell carcinoma was heterogeneous in the same patients (28) and iv) every patient in this study took everolimus and in their study, either everolimus or temsirolimus was given. On the other hand, Cho et al showed a positive association of phospho-S6 expression with tumor response in 20 patients treated with temsirolimus $(\mathrm{P}=0.02)$ and no patient without high expression of either phospho-S6 experienced an objective tumor response (29). These results are compatible with ours. We demonstrated phospho-p70 is an important protein for everolimus in vitro and in clinical samples. Thus, phospho-p70 can predict therapeutic efficacy of everolimus.

Several limitations are considered in the present study. First is the heterogeneity of renal cell carcinoma. Gerlinger et al (28) reported chromosome 3p loss and VHL aberrations were the only ubiquitous events and clear cell renal carcinomas displayed intratumor heterogeneity. Then, we had to evaluate multiple tissue samples extirpated or biopsied from primary renal tumors and metastatic lesions in the same patient. Second is the mosaic nature of the patient population. Patients in the present study received treatment as the first to fourth line in each molecular targeted drug. Then, confounding factors should be considered. However, multivariate analysis was not performed because of the small sample size. The last limitation is the small population. We should evaluate more patients in the future.

In conclusion, our results indicate that phospho-ERK,-ERK and/or -4EBP1 and -p70 are associated with responsiveness of RCC to sorafenib, sunitinib and everolimus, respectively. Based on these results, we may be able to rationally select valid molecular target agents. 


\section{References}

1. Carlomagno F, Anaganti S, Guida T, Salvatore G, Troncone G, Wilhelm SM and Santoro M: BAY 43-9006 inhibition of oncogenic RET mutants. J Natl Cancer Inst 98: 326-334, 2006.

2. Wilhelm SM, Carter C, Tang L, Wilkie D, McNabola A, Rong H, Chen C, Zhang X, Vincent P, McHugh M, et al: BAY 43-9006 exhibits broad spectrum oral antitumor activity and targets the RAF/MEK/ERK pathway and receptor tyrosine kinases involved in tumor progression and angiogenesis. Cancer Res 64: 7099-7109, 2004.

3. Escudier B, Eisen T, Stadler WM, Szczylik C, Oudard S, Siebels M, Negrier S, Chevreau C, Solska E, Desai AA, et al TARGET Study Group: Sorafenib in advanced clear-cell renal-cell carcinoma. N Engl J Med 356: 125-134, 2007.

4. Motzer RJ, Michaelson MD, Redman BG, Hudes GR, Wilding G, Figlin RA, Ginsberg MS, Kim ST, Baum CM, DePrimo SE, et al: Activity of SU11248, a multitargeted inhibitor of vascular endothelial growth factor receptor and platelet-derived growth factor receptor, in patients with metastatic renal cell carcinoma. J Clin Oncol 24: 16-24, 2006.

5. Rini BI and Small EJ: Biology and clinical development of vascular endothelial growth factor-targeted therapy in renal cell carcinoma. J Clin Oncol 23: 1028-1043, 2005.

6. Motzer RJ, Hutson TE, Tomczak P, Michaelson MD, Bukowski RM, Rixe O, Oudard S, Negrier S, Szczylik C, Kim ST, et al: Sunitinib versus interferon alfa in metastatic renal-cell carcinoma. N Engl J Med 356: 115-124, 2007.

7. Motzer RJ, Escudier B, Oudard S, Hutson TE, Porta C, Bracarda S, Grünwald V, Thompson JA, Figlin RA, Hollaender N, et al; RECORD-1 Study Group: Efficacy of everolimus in advanced renal cell carcinoma: A double-blind, randomised, placebocontrolled phase III trial. Lancet 372: 449-456, 2008.

8. Szmit S, Langiewicz P, Złnierek J, Nurzyński P, Zaborowska M, Filipiak KJ, Opolski G and Szczylik C: Hypertension as a predictive factor for survival outcomes in patients with metastatic renal cell carcinoma treated with sunitinib after progression on cytokines. Kidney Blood Press Res 35: 18-25, 2012.

9. Kust D, Prpić M, Murgić J, Jazvić M, Jakšić B, Krilić D, Bolanča A and Kusić Z: Hypothyroidism as a predictive clinical marker of better treatment response to sunitinib therapy. Anticancer Res 34: 3177-3184, 2014.

10. Di Fiore F, Rigal O, Ménager C, Michel P and Pfister C: Severe clinical toxicities are correlated with survival in patients with advanced renal cell carcinoma treated with sunitinib and sorafenib. Br J Cancer 105: 1811-1813, 2011.

11. Funakoshi T, Lee $\mathrm{CH}$ and Hsieh JJ: A systematic review of predictive and prognostic biomarkers for VEGF-targeted therapy in renal cell carcinoma. Cancer Treat Rev 40: 533-547, 2014.

12. Sheppard K, Kinross KM, Solomon B, Pearson RB and Phillips WA: Targeting PI3 kinase/AKT/mTOR signaling in cancer. Crit Rev Oncog 17: 69-95, 2012.

13. Miyake M, Ishii M, Kawashima K, Kodama T, Sugano K, Fujimoto K and Hirao Y: siRNA-mediated knockdown of the heme synthesis and degradation pathways: Modulation of treatment effect of 5-aminolevulinic acid-based photodynamic therapy in urothelial cancer cell lines. Photochem Photobiol 85: 1020-1027, 2009.

14. Miyake M, Fujimoto K, Anai S, Ohnishi S, Kuwada M, Nakai Y, Inoue $\mathrm{T}$, Matsumura $\mathrm{Y}$, Tomioka A, Ikeda $\mathrm{T}$, et al: Heme oxygenase-1 promotes angiogenesis in urothelial carcinoma of the urinary bladder. Oncol Rep 25: 653-660, 2011.

15. Zhou X, Tan M, Stone Hawthorne V, Klos KS, Lan KH, Yang Y, Yang W, Smith TL, Shi D and Yu D: Activation of the Akt/mammalian target of rapamycin/4E-BP1 pathway by ErbB2 overexpression predicts tumor progression in breast cancers. Clin Cancer Res 10: 6779-6788, 2004.
16. Garcia-Roig M, Ortiz N and Lokeshwar V: Molecular marker for predicting treatment response in advanced renal cell carcinoma: Does the promise fulfill clinical need? Curr Urol Rep 15: 375, 2014.

17. Zhang Z, Zhou X, Shen H, Wang D and Wang Y: Phosphorylated ERK is a potential predictor of sensitivity to sorafenib when treating hepatocellular carcinoma: Evidence from an in vitro study. BMC Med 7: 41, 2009.

18. Liu L, Cao Y, Chen C, Zhang X, McNabola A, Wilkie D, Wilhelm S, Lynch $M$ and Carter C: Sorafenib blocks the $\mathrm{RAF} / \mathrm{MEK} / \mathrm{ERK}$ pathway, inhibits tumor angiogenesis, and induces tumor cell apoptosis in hepatocellular carcinoma model PLC/PRF/5. Cancer Res 66: 11851-11858, 2006.

19. Campbell L, Nuttall R, Griffiths D and Gumbleton M: Activated extracellular signal-regulated kinase is an independent prognostic factor in clinically confined renal cell carcinoma. Cancer 115: 3457-3467, 2009.

20. Oka H, Chatani Y, Hoshino R, Ogawa O, Kakehi Y, Terachi T, Okada Y, Kawaichi M, Kohno M and Yoshida O: Constitutive activation of mitogen-activated protein (MAP) kinases in human renal cell carcinoma. Cancer Res 55: 4182-4187, 1995.

21. You D, Song SH, Cho YM, Lee JL, Jeong IG, Song C, Hong JH, Kim CS and Ahn H: Predictive role of tissue-based molecular markers in patients treated with sunitinib for metastatic renal cell carcinoma. World J Urol 33: 111-118, 2015.

22. Terakawa T, Miyake H, Kusuda Y and Fujisawa M: Expression level of vascular endothelial growth factor receptor-2 in radical nephrectomy specimens as a prognostic predictor in patients with metastatic renal cell carcinoma treated with sunitinib. Urol Oncol 31: 493-498, 2013.

23. Trinh XB, Tjalma WAA, Vermeulen PB, Van den Eynden G, Van der Auwera I, Van Laere SJ, Helleman J, Berns EM, Dirix LY and van Dam PA: The VEGF pathway and the AKT/mTOR/p70S6K1 signalling pathway in human epithelial ovarian cancer. Br J Cancer 100: 971-978, 2009.

24. Takeuchi A, Eto M, Shiota M, Tatsugami K, Yokomizo A, Kuroiwa K, Itsumi M and Naito S: Sunitinib enhances antitumor effects against chemotherapy-resistant bladder cancer through suppression of ERK1/2 phosphorylation. Int J Oncol 40: 1691-1696, 2012.

25. Fenton MS, Marion KM, Salem AK, Hogen R, Naeim F and Hershman JM: Sunitinib inhibits MEK/ERK and SAPK/JNK pathways and increases sodium/iodide symporter expression in papillary thyroid cancer. Thyroid 20: 965-974, 2010

26. Robb VA, Karbowniczek M, Klein-Szanto AJ and Henske EP. Activation of the mTOR signaling pathway in renal clear cell carcinoma. J Urol 177: 346-352, 2007.

27. Nishikawa M, Miyake H, Harada K and Fujisawa M: Expression level of phosphorylated-4E-binding protein 1 in radical nephrectomy specimens as a prognostic predictor in patients with metastatic renal cell carcinoma treated with mammalian target of rapamycin inhibitors. Med Oncol 31: 792, 2014.

28. Gerlinger M, Horswell S, Larkin J, Rowan AJ, Salm MP, Varela I, Fisher R, McGranahan N, Matthews N, Santos CR, et al: Genomic architecture and evolution of clear cell renal cell carcinomas defined by multiregion sequencing. Nat Genet 46: 225-233, 2014

29. Cho D, Signoretti S, Dabora S, Regan M, Seeley A, Mariotti M, Youmans A, Polivy A, Mandato L, McDermott D, et al: Potential histologic and molecular predictors of response to temsirolimus in patients with advanced renal cell carcinoma. Clin Genitourin Cancer 5: 379-385, 2007. 